\title{
Contraception for the perimenopausal woman
}

\author{
Snyman LC, BMedSci, MBChB, MPraxMed, MMed(O\&G), FCOG(SA) \\ Senior Consultant Department Obstetrics \& Gynaecology, University of Pretoria
}

Correspondence to: Dr Leon Snyman, E-mail: Leon.Snyman@up.ac.za

\section{Abstract}

Contraception in the perimenopausal transition years is a very important aspect of women's health, and it is the responsibility of all health care workers to discuss and render adequate counselling in this regard. Failure to do so can have serious health and mental consequences caused by unplanned pregnancies. There are a number of safe and effective options that one can offer these women. Most of these methods also have beneficial non-contraceptive properties.

SA Fam Pract 2007;49(4): 25-26

\section{Introduction}

Falling pregnant in the perimenopausal years can potentially have a very detrimental effect on a woman's physical as well as her mental health. Although some women do choose to be pregnant later in life, the vast majority of pregnancies of women in their mid-forties are unplanned, with termination of pregnancy rates as high as $60 \% .{ }^{1}$ Pregnancy after the age of 35 years is also associated with increased maternal and foetal morbidity. The risk for foetal aneuploidy is increased, as well as the spontaneous miscarriage rate. ${ }^{2,3}$ Maternal risks include increased risks of gestational diabetes, placenta previa, postpartum haemorrhage, malpresentations, operative delivery and premature delivery. The risks for low birth weight as well as stillbirths are also increased. ${ }^{4}$

An unplanned pregnancy in a woman in her mid to late forties will also affect the rest of the family in many different ways. It impacts on the current and future financial situation, as well as on retirement planning.

It is thus obvious that the importance of proper contraception in this group of women should not be underestimated.

\section{Physiology}

The years prior to menopause are known as the perimenopausal transitional years. This period is characterised by irregularity of menstrual cycles. The average age of onset is 46 years and average duration is 5years. ${ }^{5}$

Not only is there an accelerated loss of ovarian follicles during the perimenopause, but there is also a decrease in the productive quality of the aging follicles. This leads to a decrease in levels of inhibin A and B, with a subsequent rise in $\mathrm{FSH}$ levels, while $\mathrm{LH}$ levels remain unchanged and oestradiol levels are slightly elevated. This results initially in lengthening of the menstrual cycles, followed by prolonged periods of anovulation, subsequently causing abnormal vaginal bleeding. During this time occasional ovulation and corpus luteum function will occur, and that is the origin of the unexpected unplanned pregnancy. ${ }^{5,6}$

\section{Contraceptive Options}

Fortunately there is more than one option available regarding contraception for the perimenopausal woman. A detailed history and general as well as gynaecological examination is an essential part of the consultation, as every woman needs to be assessed regarding risks as well as contra-indications.

\section{Oral Contraception}

Combined oral contraceptives remain one of the best options in this group of patients. Not only is it very effective if used correctly, but it also provides well-known non-contraceptive benefits. These benefits include amongst others, lower risk of endometrial and ovarian cancer, reduction in menstrual blood loss, treatment of abnormal bleeding caused by anovulatory cycles and a decrease in dysmenorrhoea.

After 12 months of use there is a $50 \%$ risk reduction of developing endometrial cancer, with maximum benefit after 3 years of use. This protective effect remains for up to 20 years after discontinuation of use. The risk reduction in developing epithelial ovarian cancer in women using oral contraception is $40 \%$. After 10 years of use the risk reduction is $80 \%$. $^{7}$

Women in the perimenopausal transitional age are at higher risk of having co-morbidities such as hypertension, obesity, hyperlipidaemia and diabetes mellitus. Non smoking women with well controlled hypertension and diabetes can safely use low dose combined oral contraceptive preparations. In patients with hyperlipidaemia without vascular disease or very high levels of triglycerides, low dose oral contraception is not contra-indicated. Healthy non-smoking obese patients can also use low dose oral contraceptives.

Women over the age of 35 years who smoke should not use combined oral contraceptives, because of the very high risk of myocardial infarction observed in this group of women. The incidence of myocardial infarction in non smoking women older than 35 , using combined oral contraception, is 40 per 100000 per year, compared to 485 per 100000 per year in those over 35 years who are smokers. ${ }^{8}$ Other absolute contraindications to the use of combined oral contraception includes thromboembolic disorders, markedly impaired liver function, breast cancer, and undiagnosed abnormal vaginal bleeding.

It is safe for perimenopausal women to continue with low dose oral contraceptives until age 50, at which time FSH levels are determined on day 7 of a pillfree cycle. This is done every year and 
when $\mathrm{FSH}$ is greater than $20 \mathrm{IU} / \mathrm{L}$, the woman can be regarded as postmenopausal. ${ }^{9}$ Hormone therapy should then be considered as per indication.

The progestin-only minipill is also an option for this group of women, especially women in which oestrogen intake is contra-indicated. Fecundity (the physiological ability to reproduce) in women in the perimenopausal transitional years is markedly reduced, which increases the efficacy of the minipill. It also decreases abnormal bleeding due to anovulation. ${ }^{9}$

\section{Injectable contraceptives}

Depomedroxyprogesterone acetate has been well studied and is a very effective contraceptive. It is an option that can safely be used in perimenopausal women, especially in women where oestrogen is contra-indicated. Women with severe migraine, hypertryglyceridaemia, thromboembolic disease or smokers can make use of this form of contraception. Side -effects include depression, headaches, and irregular vaginal bleeding. ${ }^{10}$ It can also be used until the age of 50 years, or until menopausal symptoms develop. At the age of 50 , FSH levels can be measured yearly, even while the woman is on therapeutic levels, as progestin does not influence FSH levels.

\section{Intra-uterine devices}

Both the copper containing as well as the levonorgestrel intra-uterine devices are suitable for use by perimenopausal women. They are both safe and effective and they have very little side-effects and contra-indications. The levonorgestrel intra-uterine device is also registered for use in patients with menorrhagia, and the fact that many women using this device experience amenorrhea, makes it indeed a very attractive option to consider ${ }^{11}$ It can be used for between 5 and 10 years, and its effectiveness is not influenced by patient compliance or the lack thereof.

\section{Tubal ligation}

This remains a very effective means of contraception for the perimenopausal woman and in many countries around the world it is indeed the most common form of contraception. Laparoscopic tubal ligation or a procedure performed by mini laparotomy offer women, besides the anaesthetic risk, a safe method of permanent contraception with, usually, a very low complication rate. Similar protection against ovarian cancer has been reported for tubal ligation and combined oral contraceptives. ${ }^{12}$ Tubal ligation does not have any effect on the menstrual cycle. This method is an ideal option for women at the beginning of the perimenopausal transitional period, for those in whom compliance with pill taking is a problem and for women where other forms of contraception are contraindicated.

\section{Other options}

All other forms of available contraception can also be used by perimenopausal women. Periodic abstinence is not advisable as one of the features of the perimenopuasal transitional period is chronic anovulation which makes the prediction of time of ovulation virtually impossible. Barrier contraception in the form of male or female condoms is also an option that can be considered, especially when protection against sexually transmitted diseases is required. The decreased fecundity in the perimenopausal years will probably contribute to an increase in the effectiveness of barrier contraception. Vasectomy for the male partner of the perimenopausal woman should always be discussed as an option, especially in patients with contra-indications for most other forms of contraception and where there is a risk for a surgical procedure.

\section{Conclusion}

Contraception in the perimenopausal transition years is a very important aspect of women's health, and it is the responsibility of all health care workers to be able to discuss and render adequate counselling in this regard. Failure to do so can have serious health and mental consequences caused by unplanned pregnancies. There are a number of safe and effective options that one can offer these women. Most of these methods also have beneficial non-contraceptive properties. A complete history and physical examination is mandatory in order to identify the most suitable form of contraception for every individual woman..

See CPD Questionnaire, page 41

PThis article has been peer reviewed

\section{References}

1. Forrest JD. Epidemiology of unintended pregnancy and contraceptive use. AmJ Obstet Gynecol 1994;170:1485-9.

2. Hook EB, Cross PK, Schreinemachers DM. Chromosomal abnormality rates at amniocentesis and in live-born infants. JAMA 1983;249:2034-8.

3. Nybo Andersen AM, Wohlfahrt J, Christens P, Olsen J, Melbye M. Maternal age and fetal loss: population based register linkage study. BMJ 2000;320(7251):170812

4. Jolly M ,Sebire N, Haris J, Robinson S, Regan $\mathrm{L}$. The risks associated with pregnancy in women aged 35 or older. Hum Reprod 200;15:2433-7.

5. Speroff L, Glass RH, Kase NG. Clinical Gynecologic Endocrinology and Infertility. $6^{\text {th }}$ Ed. Lippincott Williams \&Wilkins 1999 p920-1.

6. Welt Ck, McNicholl DJ, Taylor AE, Hall JE. Fenale reproductive aging is marked by decreased secretion of dimeric inhibin. $J$ Clin Endocrinol Metab 1999; 84:105-11.

7. Speroff L, Glass RH, Kase NG. Clinical Gynecologic Endocrinology and Infertility. $6^{\text {th }}$ Ed. Lippincott Williams \&Wilkins 1999. p900-1.

8. Speroff L, Glass RH, Kase NG. Clinical Gynecologic Endocrinology and Infertility. $6^{\text {th }}$ Ed. Lippincott Williams \&Wilkins 1999. p891.

9. Speroff L, Glass RH, Kase NG. Clinical Gynecologic Endocrinology and Infertility. $6^{\text {th }}$ Ed. Lippincott Williams \&Wilkins 1999 p932-3.

10. Kaunitz AM. Current Concepts regarding use of DMPA. J Reprod Med 2002;47(Suppl.):785-9

11. Onyeka BA. Levonorgestrel-releasing (20 $\mathrm{mcg} /$ day) intrauterine systems (Mirena) compared with other methods of reversible contraceptives. Br J Obstet Gynecol 2001;108:770-1.

12. Speroff L, Glass RH, Kase NG. Clinical Gynecologic Endocrinology and Infertility. $6^{\text {th }}$ Ed. Lippincott Williams \&Wilkins 1999. p845. 